\title{
TECHNOLOGY
}

\section{A technique for replacing a prosthetic aortic valve after total aortic root replacement}

\author{
S Shawkat, P P Sarangi, R K Firmin
}

\begin{abstract}
The excision and replacement of a failed aortic valve bioprosthesis in a composite tubular graft in two patients with Marfan syndrome was accomplished without replacing the composite graft.
\end{abstract}

A composite tubular graft with mechanical valve prosthesis can be used to replace the ascending aorta and aortic valve in cases of Marfan syndrome. ${ }^{1}$ Some surgeons prefer to use a xenograft valve prosthesis in the composite graft. Although xenograft protheses are less likely to cause thromboembolic complications they fail more quickly and need to be replaced. We describe the use of technique for replacing a xenograft valve within such a composite graft without having to re-do cardiac, aortic, or coronary anastomoses in two patients.

\section{Case reports}

CASE 1

A 39 year old man with Marfan syndrome presented to our unit with increasing breathlessness. Eleven years previously he had undergone mitral valve replacement with a 33 mm Carpentier-Edwards bioprosthesis. Four years later he underwent composite aortic root replacement with reimplantation of the coronary arteries with a $30 \mathrm{~mm}$ woven Dacron graft to which a $25 \mathrm{~mm}$ Carpentier-Edwards prothesis was sewn. On admission to our unit investigation showed severe aortic regurgitation. At operation full cardiopulmonary bypass was established with pump return to the right femoral artery. The patient was core cooled to $25^{\circ} \mathrm{C}$. The aortic graft was cross clamped and opened obliquely. Cold St Thomas's cardioplegia mixture was infused into the coronary ostia and topical cooling was added. The failed aortic bioprothesis had severe calcification with leaflet tears and was freely incompetent. The stent part of the valve was excised leaving the sewing ring behind (fig 1) and the proximal graft suture line intact. A $23 \mathrm{~mm}$ St Jude aortic prothesis was inserted with interrupted $2 / 0$ Ethibond sutures. The procedure was completed uneventfully. He was discharged on the 10th postoperative day and remains well with normal aortic and mitral valve function a year later.

CASE 2

A 36 year old woman with Marfan syndrome had undergone composite root replacement with reimplantation of the coronary arteries at another hospital six years before. A $27 \mathrm{~mm}$ Carpentier-Edwards valve had been sewn into a $30 \mathrm{~mm}$ Dacron conduit. She was admitted to a district hospital with breathlessness and signs of heart failure one month before operation. Then she was transferred to our hospital. She had pronounced oedema. Cardiac catheterisation indicated aortic regurgitation and stenosis and mild mitral ' regurgitation-all judged to be functional. Her coagulation fac-
Cardio Thoracic Unit, Groby Road Hospital, Leicester S Shawkat P P Sarangi R K Firmin

Correspondence to Mr S Shawkat, FRCS, Groby Road Hospital, Leicester LE3 9QE.

Accepted for publication 20 December 1989

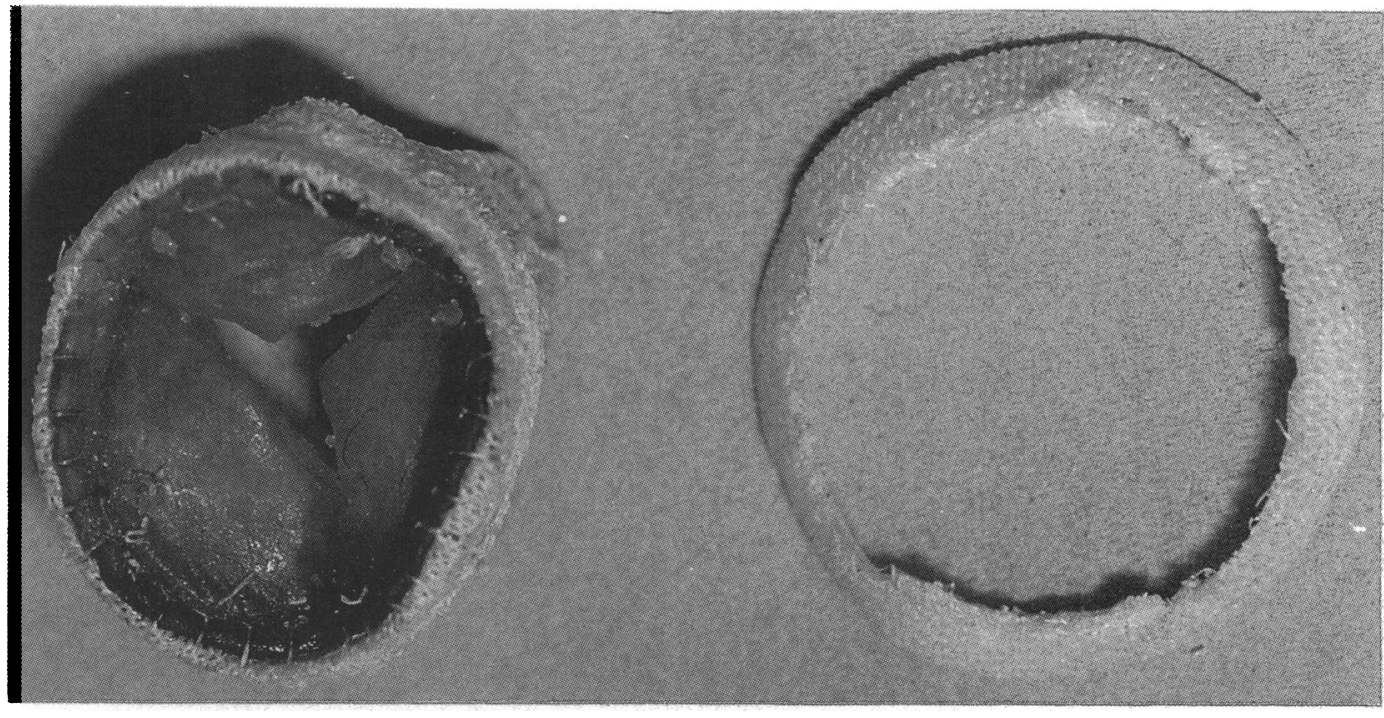

Figure 1 It is possible to dissect the stent part of the valve from the sewing ring. 
Figure 2 A St Jude valve in place after excision of the failed bioprothesis in patient 2.

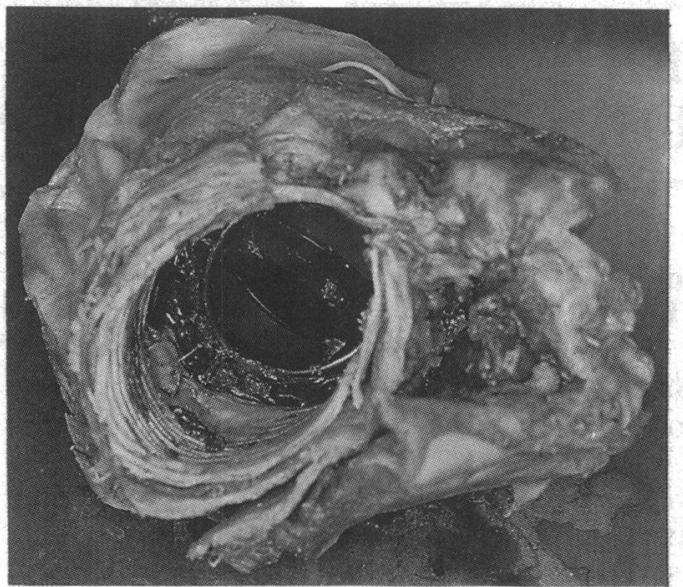

tors and electrolyte concentrations were grossly abnormal. At emergency operation she had the $27 \mathrm{~mm}$ aortic bioprothesis removed and a $23 \mathrm{~mm} \mathrm{St} \mathrm{Jude} \mathrm{valve} \mathrm{inserted} \mathrm{in} \mathrm{exactly}$ the same way as the first patient (fig 2). Again the bioprothesis was severely calcified and had leaflet tears. Although the ischaemic time was less than 60 minutes cardiac output was low after operation and she died 48 hours later. Necropsy showed that the operation had been successfully accomplished; the mitral annulus was dilated and the myocardium was fibrotic.
It was likely that death was caused by a combination of mitral regurgitation, which was more severe than we had assessed, and myocardial failure.

\section{Discussion}

The argument for using a bioprothesis in a composite root is essentially the same as for simple valve replacement. Many patients who undergo aortic root replacement, however, have Marfan syndrome and are liable to have cardiovascular problems at other sites. Anticoagulation is a significant disadvantage in such patients. Unfortunately patients are generally young and standard bioprotheses tend to degenerate more rapidly in them than in older patients. The choice of valve for individual cases is thus difficult. We showed that the excision and replacement of a failed bioprothesis in a composite root is not technically difficult and that it is unnecessary to replace the whole composite graft.

1 Bentall M, DeBono A. A technique for complete replacement of ascending aorta. Thorax 1968;23:338-9. 